\title{
Penetração de Cloretos em Concretos com Substituição Parcial do Aglomerante Pelo Resíduo do Beneficiamento de Rochas OrNamentais
}

\author{
Teixeira. Fernando Ritiéle \\ Engenheiro Civil \\ Universidade Federal de Pelotas \\ Rio Grande do Sul ; Brasil \\ Fernandoteixeira5400@gmail.com \\ Paliga . Charlei Marcelo \\ Professor Doutor \\ Universidade Federal de Pelotas \\ Rio Grande do sul ; Brasil \\ charleipaliga@gmail.com
}

\author{
Costa. Vitória Silveira da \\ Arquiteta e Urbanista \\ Universidade Federal de Pelotas \\ Rio Grande do sul ; Brasil \\ vitoriascosta@yahoo.com.br \\ Torres. Ariela da Silva \\ Professora Doutora \\ Universidade Federal de Pelotas \\ Rio Grande do sul ; Brasil \\ arielatorres@gmail.com
}

\section{RESUMO}

Os íons cloreto representam uma ameaça à integridade das armaduras em estruturas de concreto armado. Assim sendo, é de vital importância conhecer o comportamento do concreto frente à ação desse agente agressivo, com o intuito de determinar a sua adequação ao ambiente onde será empregado. Desta maneira, realizou-se um estudo da penetração de cloretos em concretos com substituição parcial do cimento pelo resíduo do beneficiamento de rochas ornamentais (RBRO) em ambiente de laboratório. Para tanto, adotou-se um traço de concreto de referência produzido com cimento CP V-ARI, a partir da dosagem pelo Método IPT/EPUSP. O resíduo foi utilizado em proporções de 5\%, 7,5\% e 10\% de substituição em massa ao cimento. O RBRO foi caracterizado mineralogicamente por ensaios de difração de raios X $(\mathrm{DRX})$, microanálise de raios $\mathrm{X}(\mathrm{EDX})$ e fisicamente por ensaios de granulometria à laser e massa específica. A penetração de cloretos foi avaliada por aspersão de nitrato de prata $\left(\mathrm{AgNO}_{3}\right)$, após imersão em solução de cloretos a uma concentração de 3,5\% por seis meses. A verificação da profundidade da penetração dos íons cloretos se deu por meio de imagens digitais e o auxílio do software AutoCAD. Os resultados demonstram uma menor profundidade da penetração de cloretos em concretos com substituição do cimento por RBRO em comparação ao traço de referência.

Palavra-Chave: tecnologia da arquitetura; aproveitamento de resíduo; resíduo do beneficiamento de rochas ornamentais; penetração de ions cloreto.

\begin{abstract}
Chloride ions pose a threat to the integrity of reinforcements in reinforced concrete structures. Therefore, it is vitally important to know the behavior of concrete against the action of this aggressive agent, in order to determine its suitability to the environment where it will be employed. In this way, a study of the penetration of chlorides in concretes with partial replacement of the cement by the residue of the ornamental rocks processing (RBRO) was carried out. For this, a trace of reference concrete produced with CP V-ARI cement was adopted from the IPT / EPUSP method. The residue was used in proportions of $5 \%, 7.5 \%$ and $10 \%$ of mass substitution to the cement. The RBRO was characterized mineralogically by X-ray diffraction (XRD), X-ray microanalysis (EDX) and physically by laser and specific mass granulometry assays. The chloride penetration was evaluated by silver nitrate spray (AgNO3), after immersion in chloride solution at a concentration of $3.5 \%$ for six months. The penetration depth of chloride ions was verified by means of digital images and the aid of AutoCAD software. The results demonstrate a lower depth of penetration of chlorides in cement replacement concrete by RBRO compared to the reference trait.
\end{abstract}

Keywords: architecture technology; waste utilization, ornamental rock processing residue; chloride ion penetration 


\section{INTRODUÇÃO}

O concreto é o material mais utilizado na indústria da construção civil e também o principal insu mo na maior parte das obras de infraestrutura realizadas (BANSAL et al., 2017). Ribeiro e Cascudo (2018) afirmam que os avanços das metodologias de dimensionamento estrutural e dos sistemas construtivos contribuem à crescente ocorrência de estruturas mais esbeltas e com menor cobrimento da armadura, podendo, assim, reduzir a durabilidade das construções. Devido ao desempenho inadequado de muitas estruturas construídas nas últimas décadas frente à durabilidade, a importância dada aos projetos de durabilidade e às previsões de vida útil é cada vez maior (BEUSHAUSEN e LUCO, 2016). A corrosão das armaduras causada pela ação de íons cloreto, sejam eles provenientes de atmosferas marinhas ou de sais de degelo, é a principal causa da deterioração precoce de estruturas em concreto armado (CAO et al., 2019)

Ollivier e Torrenti (2014) destacam que quanto maior for a dificuldade imposta ao ingresso de agentes agressivos na estrutura de poros do concreto, mais durável este será. Somam-se, ainda, a este fator, as características químicas da pasta cimentícia e as condições às quais o concreto é exposto (NEVILLE, 2010).

Frente a esse cenário, a utilização de subprodutos de diversos setores da indústria, os quais normalmente não são biodegradáveis e perduram por muitos anos no meio ambiente, tem sido largamente estudada em busca de concretos menos suscetíveis à penetração de íons nocivos e com vistas à sustentabilidade, uma vez que a indústria cimenteira é fonte geradora de elevados teores de $\mathrm{CO}_{2}$ (SOGANCIOGLU et al., 2016). Vários estudos apontam que a utilização desses materiais é capaz de gerar melhorias nas propriedades mecânicas, de durabilidade e de trabalhabilidade do concreto, além de reduzir os custos de sua produção e o impacto ambiental (CORINALDESI e MORICONI, 2016).

Entre esses subprodutos estão os resíduos de beneficiamento de rochas ornamentais (RBRO). Segundo a Associação Brasileira da Indústria de Rochas Ornamentais, em 2017 a produção de rochas no Brasil foi de aproximadamente 9,24 Mt, sendo 1,046 Mt para exportação. Salienta-se que, em volume, 41\% dos blocos de rochas são transformados em rejeitos, gerando cerca 3,36 Mt de material descartável durante o processamento das rochas ornamentais (ABIROCHAS, 2017). Garas, Allam e Bakhoum (2014) afirmam que a utilização de resíduos do beneficiamento de rochas ornamentais (RBRO) se mostra promissora na mitigação de impactos ambientais, no desenvolvimento sustentável da construção civil e na melhoria de propriedades do concreto.

A utilização de resíduos provenientes do beneficiamento de mármore também tem sido tema de diversos estudos atualmente. Rana, Kalla e Csetenyi (2015) constataram uma menor concentração dos íons cloreto no interior do concreto contendo 5 a $10 \%$ de resíduo do mármore em substituição ao cimento, em relação ao concreto de referência. Segundo os autores, essa redução da penetração dos íons cloro foi ocasionada pelo efeito filler, que refinou a estrutura dos poros. Rodrigues et al. (2015) utilizaram 0\%,5\%, 10\% e 15\% do resíduo do beneficiamento do mármore em substituição ao cimento para examinar o comportamento mecânico do concreto. Melhorias na resistência do concreto foram observados em teores de substituição de até $10 \%$. Segundo o autor, as melhorias no comportamento mecânico foram atribuídas ao efeito filler, que densificou a zona de transição. Ramos et al. (2013), em um estudo que consistia na produção de argamassas substituindo o cimento por resíduo de granito, atribuíram a redução no ingresso de cloretos nas misturas ao fato da formação de cloroaluminatos, provenientes da combinação da alumina $\left(\mathrm{Al}_{2} \mathrm{O}_{3}\right)$, presente no resíduo, com os íons cloreto, formando o sal de Friedel (C-A-H).

Com o intuito de aproveitar as propriedades desse material para aplicação em concretos estruturais, o presente trabalho aborda o desempenho de concretos com substituição parcial do cimento pelo RBRO frente a ação de íons cloretos.

\section{PROGRAMA EXPERIMENTAL}

\subsection{Materiais e métodos}

\subsubsection{Cimento}

O cimento utilizado nesta pesquisa foi o CP V-ARI da marca Supremo Secil, pois possui adições sem reatividade conforme NBR 12653 (ABNT, 2014), o que facilita a compreensão da ação do RBRO, e evita efeitos combinados, possibilitando uma visualização mais clara dos efeitos da substituição do cimento pelo RBRO no concreto.

\subsubsection{Agregados}

Foi utilizada uma areia natural quartzosa, média, enquadrada na zona utilizável da NBR 7211 (ABNT, 2009), seca em estufa até constância de massa. A brita granítica utilizada foi classificada como brita 1 de acordo com a NBR 7211 (ABNT, 2009). Os agregados foram adquiridos em areais da cidade de Pelotas/RS, sendo os resultados da caracterização física obtidos dos agregados naturais apresentados na Tabela 1.

Tabela 1 - Caracterização dos agregados. 


\begin{tabular}{|c|c|c|c|}
\hline \multicolumn{2}{|l|}{ Tipo de ensaio } & $\begin{array}{l}\text { Agregado } \\
\text { miúdo }\end{array}$ & Agregado graúdo \\
\hline \multirow{2}{*}{$\begin{array}{l}\text { Composição granulométrica/ NBR NM } 248 \text { (ABNT, } \\
\text { 2003) }\end{array}$} & $\varnothing$ máx (mm) & 4,75 & 19 \\
\hline & $\begin{array}{l}\text { Módulo de } \\
\text { Finura }\end{array}$ & 2,84 & 4,69 \\
\hline \multicolumn{2}{|c|}{$\begin{array}{l}\text { Massa específica }\left(\mathrm{g} / \mathrm{cm}^{3}\right) / \text { NBR NM } 52(\mathrm{ABNT}, 2009) \text { e NBR NM } 53 \\
(\mathrm{ABNT}, 2009)\end{array}$} & 2,62 & 2,60 \\
\hline \multicolumn{2}{|c|}{ Massa unitária solta (g/cm³) / NBR NM 45 (ABNT, 2006) } & 1,55 & 1,41 \\
\hline
\end{tabular}

\subsubsection{RBRO}

O RBRO, coletado na forma de lama, foi gerado por uma empresa beneficiadora de mármores e granitos, localizada na cidade de Pelotas/RS. A coleta, segundo a NBR 10007 (ABNT, 2004), foi feita diretamente do tanque de decantação da empresa, sendo que todo material utilizado no trabalho foi coletado no mesmo dia. Após a coleta o material passou por um processo de homogeneização e quarteamento para a obtenção de uma amostra representativa. Na sequência a lama do RBRO foi colocada em estufa, onde permaneceu por 48 horas a uma temperatura de $100^{\circ} \mathrm{C}$. Em seguida, o resíduo foi passado na peneira de abertura $1,18 \mathrm{~mm}$, para retirada de eventuais impurezas e destorroamento, eliminando, desta forma, a necessidade de moagem. Uma vez destorroado, o resíduo é finalmente passado na peneira de abertura da malha de $300 \mu \mathrm{m}$. Finalizando, o resíduo peneirado foi armazenado em sacos, estando pronto para ser utilizado. O RBRO apresentou massa específica de 2,64 g/ $\mathrm{cm}^{3}$, segundo a NBR NM 23 (ABNT, 2001) e massa unitária de $1,16 \mathrm{~g} / \mathrm{cm}^{3}$ conforme a NBR NM 45 (ABNT, 2006).

Foi determinada a granulometria do RBRO, em granulômetro a laser da Cilas, modelo 1064. Esse ensaio foi realizado no laboratório de Ciências dos Materiais da UFPEL. Na figura 1 estão apresentados os dados obtidos no ensaio. A análise da curva mostra que o diâmetro médio de partícula do RBRO é de $30,95 \mu \mathrm{m}$.

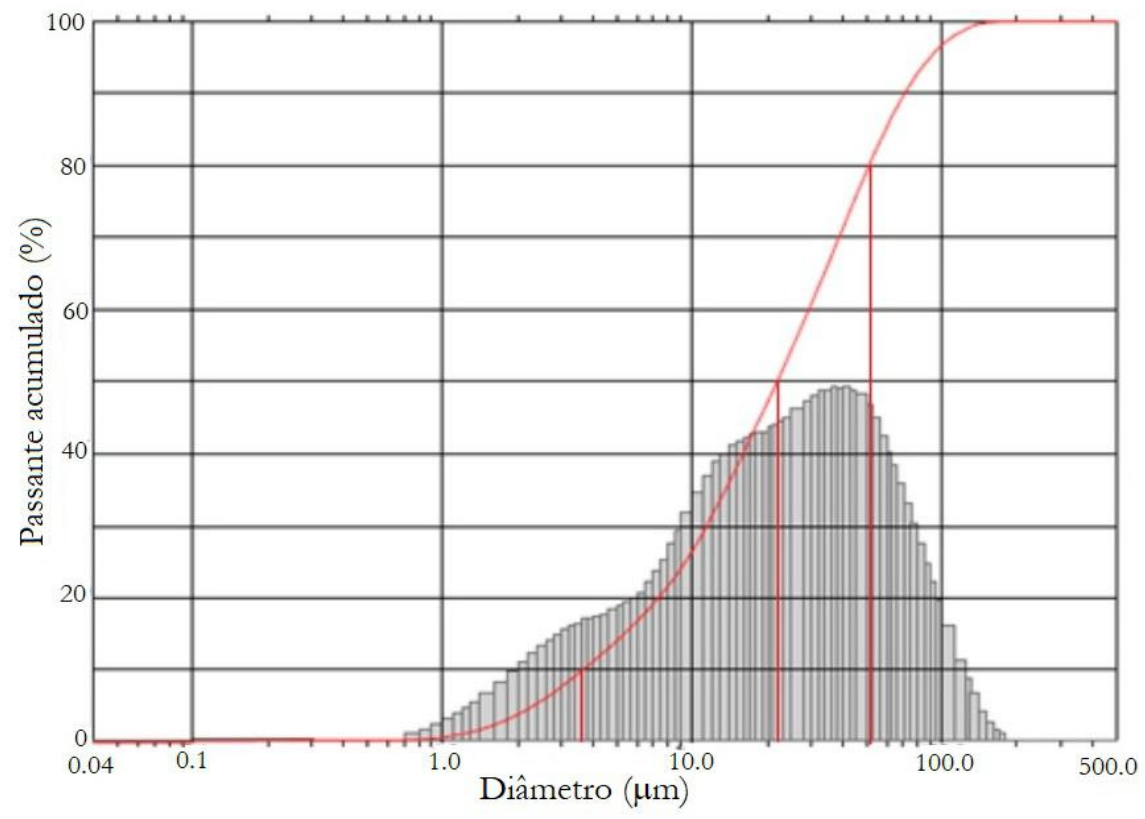

Figura 1 - Curva granulométrica do RBRO.

Para identificar a presença de elementos cristalinos na composição do RBRO foi realizada uma análise de difração de raios X (DRX), no Centro de Microscopia Eletrônica da Zona Sul (CEME-SUL) da Universidade Federal do Rio Grande (FURG), utilizando-se um difratômetro Shimadzu, modelo XRD 6000, operando com radiação de $\mathrm{CuK} \alpha$ $(=1,5418 \AA)$ e monocromador de grafite, operando a uma tensão de $40 \mathrm{kV}$ e corrente de $30 \mathrm{~mA}$, na faixa de varredura 
de 5 a $80^{\circ}$ e velocidade angular de $2^{\circ} / \mathrm{min}$. A figura 2 apresenta o difratograma de raios X do resíduo. Analisando-o foi possível verificar que o RBRO em estudo é constituído principalmente por quartzo (Q) e Albita (A). Podem ser observados, também, picos menos intensos de Microclina (M) e Biotita (B). Através do ensaio é constatada pouca reatividade do RBRO em decorrência da mesma apresentar um pico cristalino bem definido referente ao quartzo $\left(\mathrm{SIO}_{2}\right)$ e ausência de halo amorfo.

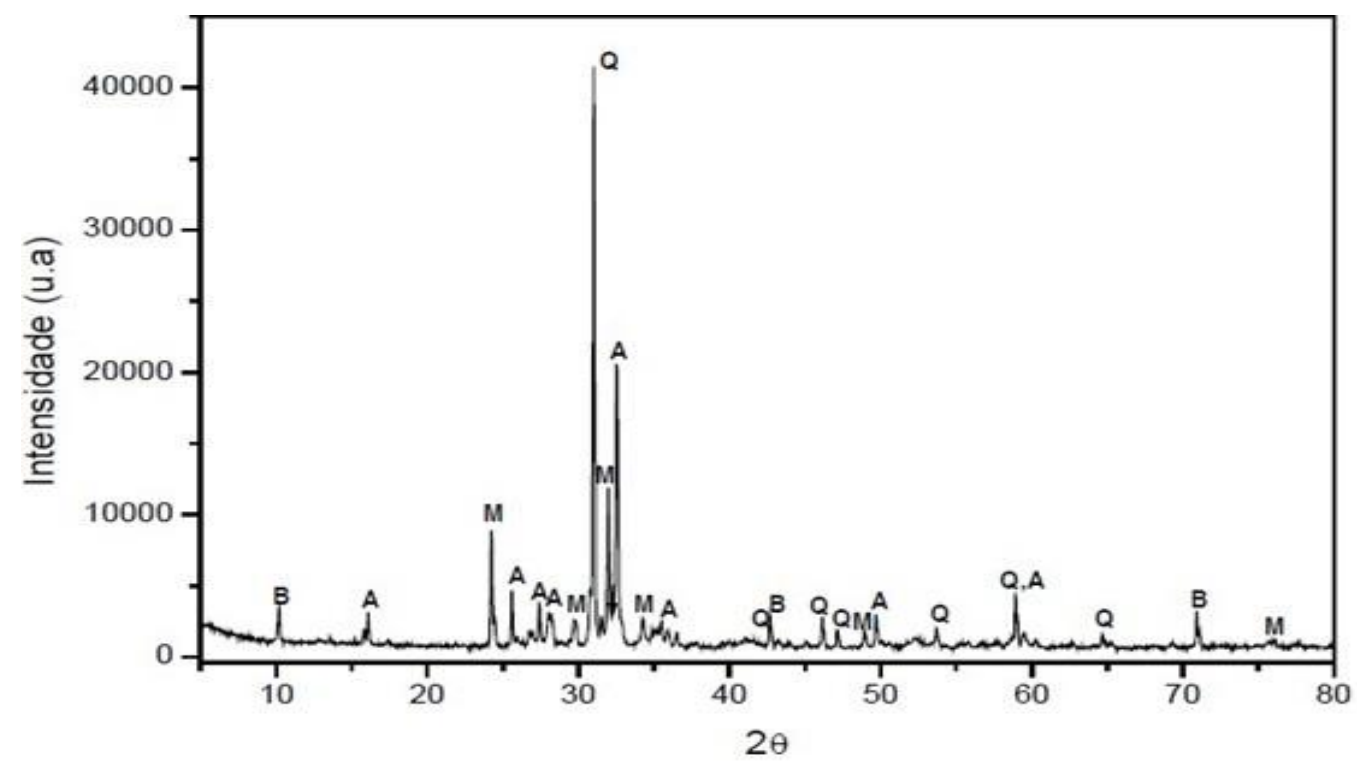

Figura 2 - Difratograma de uma amostra de RBRO

A composição química do RBRO foi determinada no Laboratório de Nanotecnologia Novonano da UFPEL e utilizou um espectrômetro de fluorescência de raios x por dispersão de energia, modelo Shimadzu EDX-720. Na tabela 2 está apresentado o resultado deste ensaio.

Tabela 2 - Composição química do RBRO

\begin{tabular}{|c|c|}
\hline Elemento & Quantitativo (\%) \\
\hline $\mathrm{SiO}_{2}$ & 34,085 \\
\hline $\mathrm{K}_{2} \mathrm{O}$ & 20,287 \\
\hline $\mathrm{Al}_{2} \mathrm{O}_{3}$ & 18,770 \\
\hline $\mathrm{Fe}_{2} \mathrm{O}_{3}$ & 12,570 \\
\hline $\mathrm{CaO}$ & 12,181 \\
\hline $\mathrm{TiO}_{2}$ & 1,444 \\
\hline $\mathrm{MnO}_{2}$ & 0,178 \\
\hline $\mathrm{ZnO}$ & 0,122 \\
\hline $\mathrm{ZrO}$ & 0,118 \\
\hline $\mathrm{SrO}_{2}$ & 0,103 \\
\hline $\mathrm{CuO}_{2}$ & 0,101 \\
\hline $\mathrm{Rb}{ }_{2} \mathrm{O}$ & 0,024 \\
\hline $\mathrm{Y}_{2} \mathrm{O}_{3}$ & 0,006 \\
\hline & \\
\hline
\end{tabular}

Segundo a NBR 12653 (ABNT, 2014), a soma dos óxidos $\mathrm{SiO}_{2}, \mathrm{Al}_{2} \mathrm{O}_{3}$ e $\mathrm{Fe}_{2} \mathrm{O}_{3}$ deve ser superior a 70\% para que o material analisado seja considerado pozolânico. A soma dos mesmos foi de $62,42 \%$, onde, de acordo com a NBR 12653 (ABNT, 2014), o material não é considerado pozolânico, apresentando apenas efeito físico. 


\subsubsection{Cloreto de sódio}

O cloreto de sódio foi utilizado na forma de cloreto de sódio $\mathrm{Pa}(\mathrm{NaCl})$, solução em pó, para preparação da solução salina para imersão dos corpos de prova no ensaio de penetração de íons cloreto em laboratório. Foram empregados $35 \mathrm{~g}$ de $\mathrm{NaCl}$ dissolvidos em cada litro de água, para simular a salinidade do Oceano Atlântico (HELENE,1993).

\subsection{PRODUÇÃO E AVALIAÇÃO DOS CONCRETOS}

Para a dosagem dos concretos utilizou-se a metodologia de dosagem do IPT/EPUSP (HELENE e TERZIAN, 1993). Através de procedimento experimental definiu-se o teor de argamassa seca ideal em $51 \%(\alpha=0,51)$ e a quantidade de água necessária para a obtenção do abatimento do tronco de cone em $70 \pm 10 \mathrm{~mm}$. Os resultados do ajuste da dosagem estão apresentados na tabela 3 .

Tabela 3 - Resultados do ajuste da curva de dosagem experimental

\begin{tabular}{|c|c|c|c|c|}
\hline Traço unitário & Relação a/c & $\mathrm{Fc}_{28}$ Médio (MPa) & Consumo de cimento $\left(\mathrm{kg} / \mathrm{m}^{3}\right)$ & Abatimento (cm) \\
\hline $1 ; 3,5$ & 0,41 & 45 & 493,37 & 6,8 \\
\hline $1 ; 5,0$ & 0,50 & 38 & 376,67 & 7,2 \\
\hline $1 ; 6,5$ & 0,69 & 28 & 297,05 & 7,4 \\
\hline
\end{tabular}

Através do valor pré-estabelecido da relação água/cimento de 0,60 e das curvas de dosagem obtidas por regressão linear simples pelo método dos mínimos quadrados, foi determinado o traço de referência do concreto, conforme tabela 4 . A relação água/cimento igual a 0,60 foi definida por ser o valor máximo considerado para um concreto estrutural, localizado em ambiente urbano (Classe II de agressividade), de acordo com a NBR 6118 (ABNT, 2014).

A partir do traço de referência foi realizada a substituição parcial do cimento pelo RBRO em teores de $5 \%, 7,5 \%$ e $10 \%$.

Tabela 4 - Traços unitários utilizados na confecção dos corpos de prova

\begin{tabular}{|c|c|c|c|c|c|c|}
\hline Traço & Cimento (kg) & RBRO (kg) & Areia (kg) & Brita (kg) & Fator a/c & $\mathbf{N}^{\circ}$ de corpos de prova \\
\hline Referência & 1 & 0 & 2,4 & 3,28 & 0,6 & 4 \\
\hline $5,0 \%$ & 0,95 & 0,05 & 2,4 & 3,28 & 0,6 & 4 \\
\hline $7,50 \%$ & 0,925 & 0,075 & 2,4 & 3,28 & 0,6 & 4 \\
\hline $10,0 \%$ & 0,9 & 0,1 & 2,4 & 3,28 & 0,6 & 4 \\
\hline
\end{tabular}

\subsection{ENSAIO DE PENETRAÇ̃̃O DE ÍONS CLORETO POR IMERSÃO EM SOLUÇ̃̃O SALINA}

Foi realizado ensaio de penetração de íons cloreto por imersão em solução salina com duração de seis meses para que a penetração de cloretos ocorresse naturalmente, simulando uma situação real. A solução de cloretos foi produzida a partir da dissolução de cloreto de sódio $(\mathrm{NaCl})$ a uma concentração de $3,5 \%$, conforme a concentração média verificada nos oceanos. Os corpos de prova (cilíndricos com 10x20 cm) foram parcialmente imersos. O procedimento da imersão parcial consistiu em colocar os corpos-de-prova em um recipiente contendo a solução salina descrita anteriormente, de tal forma que o nível dessa solução correspondesse a 1/3 da altura dos corpos-de-prova. A solução era substituída a cada três meses, de maneira a garantir o nível de aeração adequado ao desenvolvimento da penetração de íons cloreto. Foi realizada uma marcação nos corpos de prova para controlar a altura da solução salina e repor a solução em caso de evaporação.

\subsection{MEDIÇÃO DA PROFUNDIDADE DE CLORETOS}

Na idade preestabelecida quatro corpos-de-prova por traço foram rompidos à tração por compressão diametral e, após, submetidos à aspersão de solução de nitrato de prata $(0,10 \mathrm{~N}$ em água deionizada). A verificação da profundidade da penetração dos íons se deu por meio de imagens digitais e o auxílio do software AutoCAD. A aplicação de nitrato de prata (AgNO3) resulta em uma cor esbranquiçada nos locais onde existem cloretos livres em concentração superior a $0,15 \%$. Onde não há cloretos, a coloração se torna marrom. Para a medição da profundidade de penetração de cloretos foi utilizada a preconização da NT BUILD 492 (1999), que determina verificar medidas a cada 10 mm, sendo o resultado a média entre todas elas.

Com a profundidade média estabelecida para cada idade os valores de cada traço foram analisados através de funções de regressão, resultando em equações, conforme apresentado a seguir. Delas foram obtidos o coeficiente de penetração "k". 


$$
x=k \sqrt{t}
$$

(Equação 1)

Onde:

x- Profundidade de penetração (mm);

$\mathrm{k}$ - Coeficiente de penetração;

$\mathrm{t}$ - Tempo (semanas).

\section{RESULTADOS E DISCUSSÃO}

Os valores obtidos no ensaio de penetração de íons cloreto por imersão em solução salina durante seis meses são mostrados na tabela 5 e na figura 3.

Tabela 5 - Penetração de cloretos e coeficiente de penetração após 6 meses de imersão

DP: Desvio-padrão, CV: Coeficiente de variação, k: Coeficiente de penetração de íons cloretos

\begin{tabular}{|c|c|c|c|c|}
\hline Teor de substituição & Penetração de cloretos média $(\mathbf{m m})$ & $\begin{array}{c}\mathbf{D P} \\
(\mathbf{m m})\end{array}$ & $\mathbf{C V}(\mathbf{\%})$ & $\mathbf{k}(\mathbf{m m} / \sqrt{ }$ semana) médio \\
\hline Referência & 25,66 & 2,06 & 8,06 & 5,247 \\
\hline $5,0 \%$ & 23,99 & 2,89 & 12,09 & 4,905 \\
\hline $7,5 \%$ & 23,013 & 1,31 & 5,73 & 4,706 \\
\hline $10,0 \%$ & 25,158 & 1,04 & 4,14 & 5,144 \\
\hline
\end{tabular}

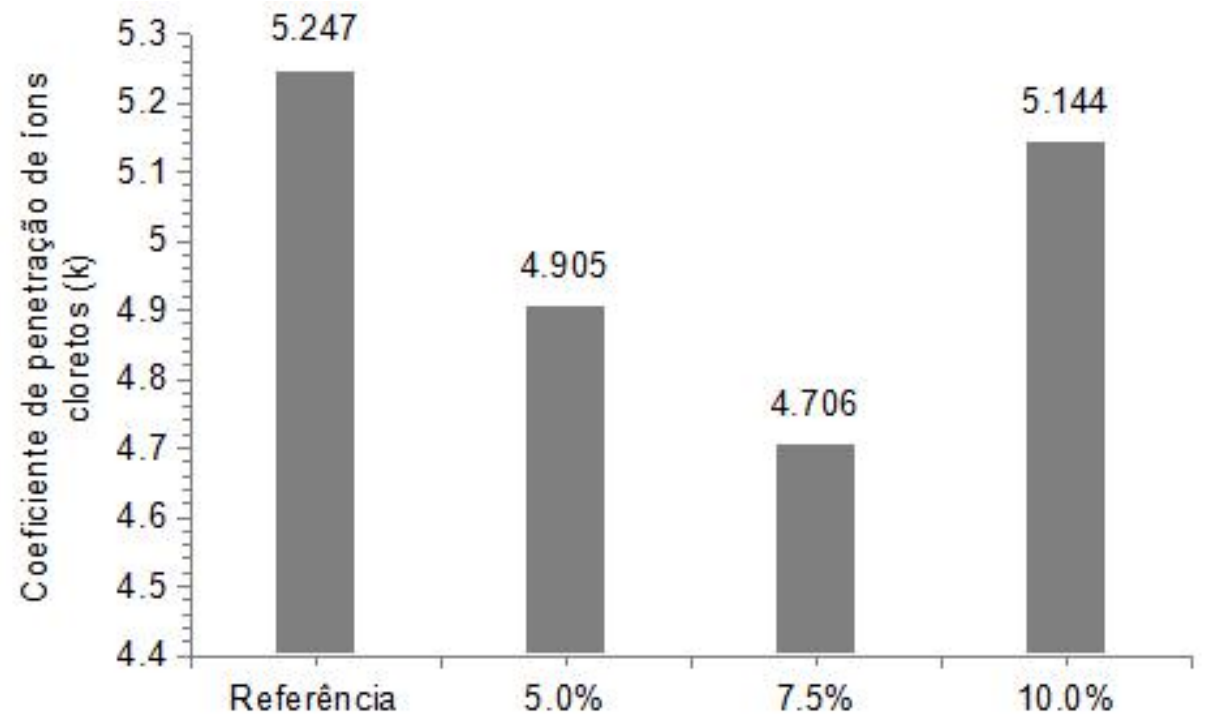

Figura 3 - coeficiente de penetração de íons cloretos.

Constatou-se que a utilização do RBRO dessa pesquisa promoveu uma leve redução na penetração de cloretos, corroborando o apresentado por Garas, Allam e Bakhoum (2014), Dietrich, Teles e Vieira (2017) e Mittri (2016). Segundo os autores, a redução nos valores pode ser explicada pela formação de cloroaluminatos, provenientes da combinação da

alumina $\left(\mathrm{Al}_{2} \mathrm{O}_{3}\right)$, presente no resíduo, com os íons cloreto, formando o sal de Friedel $(\mathrm{C}-\mathrm{A}-\mathrm{H})$ e pelo efeito filler (efeito de preenchimento dos poros) na microestrutura do concreto.

Do mesmo modo, Ramos et al. (2013) concluiu que a substituição do cimento pelo RBRO em até $20 \%$ aumentou a resistência à penetração dos íons cloreto devido à densificação da microestrutura. $\mathrm{O}$ autor também atribuiu a redução no ingresso de cloretos nas misturas em decorrência da formação de cloroaluminatos, provenientes da combinação da alumina $\left(\mathrm{Al}_{2} \mathrm{O}_{3}\right)$, presente no resíduo, com os íons cloreto, formando o sal de Friedel $(\mathrm{C}-\mathrm{A}-\mathrm{H})$.

Rana, Kalla e Csetenyi (2015) constataram uma menor concentração dos íons cloreto no interior do concreto contendo 5 a $10 \%$ de resíduo do mármore em substituição ao cimento, em relação ao concreto de referência. Segundo os autores, essa redução da penetração dos íons cloro foi ocasionada pelo efeito filler, que refinou a estrutura dos poros. 


\section{CONSIDERAÇÕES FINAIS}

Neste trabalho procurou-se verificar a influência exercida na substituição parcial do cimento pelo RBRO na penetração de íons cloreto.

Tendo em vista os resultados obtidos, foi possível concluir que:

- Os traços com substituição parcial do cimento pelo RBRO apresentaram coeficientes de penetração de íons cloreto menores que o traço de referência;

- Os resultados do estudo demonstram que a substituição parcial do aglomerante por RBRO é satisfatoriamente viável quanto ao critério de penetração de íons cloreto.

\section{REFERÊNCIAS}

ABIROCHAS - Associação Brasileira da Indústria de Rochas Ornamentais. Exportações e Importações Brasileiras de Rochas. ABIROCHAS, 2017. Disponível em: <http://www.abirochas.com.br/estatisticas.php>. Acesso em: 22 abr. 2018.

ASSOCIAÇÃO BRASILEIRA DE NORMAS TÉCNICAS (ABNT). NBR 6118 - Projeto de estruturas de concreto Procedimento. Rio de Janeiro, 2014.

NBR 10007 - Amostragem de resíduos sólidos. Rio de Janeiro, 2004.

NBR 12653 - Materiais pozolânicos - Requisitos. Rio de Janeiro, 2014.

NBR 7211 - Agregados para concreto - Especificação. Rio de Janeiro, 2009.

NBR NM 248 - Agregados - Determinação da composição granulométrica. Rio de Janeiro, 2003

NBR NM 45 - Agregados - Determinação da massa unitária e do volume de vazios. Rio de Janeiro, 2006.

NBR NM 52 - Agregado miúdo - Determinação da massa específica e massa específica aparente. Rio de Janeiro, 2009.

NBR NM 53 - Agregado graúdo - Determinação da massa específica, massa específica aparente e absorção de água. Rio de Janeiro, 2003.

BANSAL, B. K., CHOUHAN, D. S., GUPTA, T., SHARMA, R. K. Behavior of concrete utilizing metakaolin: A review. European Journal of Advances in Engineering and Technology, v. 4, p. 549-554, 2017.

BEUSHAUSEN, H.; LUCO, O. F. Performance-based specifications and control of concrete durability. RILEM TC 230-PSC State-of-the-Art Report. Springer, New York, 2016.

CAO, Y., GEHLEN, C., ANGST, U., WANG, L., WANG, Z., YAO, Y. Critical chloride content in reinforced concrete - An update review considering Chinese experience. Cement and Concrete Research, v.117, p.58-68, 2019.

CORINALDESI, V., MORICONI, G. Recycling of rubble from building demolition for low shrinkage concretes. Waste Management, v.30, p. 655-659,2010.

DIETRICH, Y. P.; TELES, C. R.; VIEIRA, G. L. Mechanical performance and reinforcement steel corrosion process in concrete containing ornamental rock waste. Revista Materia, v. 22, n. 4, p. 14, 2017.

GARAS, G. L., ALLAM, M. E., BAKHOUM, E. S. Studies undertaken to incorporate marble and granite wastes in green concrete production. ARPN Journal of Engineering and Applied Sciences, v.9, p.1559-1564, 2014.

HELENE, P. R. L.; TERZIAN, P. Manual de dosagem e controle do concreto. São Paulo: PINI, 1993. 349 p.

HELENE, P.R.L. Contribuição ao estudo da corrosão e armaduras de concreto armado. 1993. 231f. Tese (Doutorado em Engenharia) - Escola Politécnica, Universidade de São Paulo, São Paulo, 1993. 
MITTRI, S. H. M. Contribuição ao estudo do comportamento de concretos produzidos com resíduo do beneficiamento de rochas ornamentais tratado termicamente em relação aos aspectos mecânicos e de durabilidade. Dissertação (Mestrado) - Universidade Federal do Espírito Santo, Vitória, 2016.

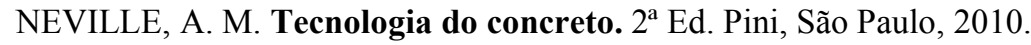

NT Build 492 - NORDTEST METHOD. Concrete, mortar and cement-based repair materials: Chloride migration coefficient from non-steady-state migration. 1999.

OLLIVIER, J. P.; TORRENTI, J. M., 2014. A estrutura porosa dos concretos e as propriedades de transporte. In: Durabilidade do concreto: Bases científicas para a formulação de concretos duráveis de acordo com o ambiente (Ed. Traduzida). São Paulo, IBRACON, 2014.

RAMOS, T. et al. Granitic quarry sludge waste in mortar: Effect on strength and durability. Construction and Building Materials, v. 47, p. 1001-1009, 2013.

RANA, A.; KALLA, P.; CSETENYI, L. J. Sustainable use of marble slurry in concrete.J. Clean. Prod., v. 94, p. 304e311, 2015.

RIBEIRO, D. V.; CASCUDO, O., 2018. Durabilidade e vida útil das estruturas de concreto. In: Corrosão e Degradação em Estruturas de Concreto - Teoria, controle e técnicas de análise e intervenção. Elsevier, Rio de Janeiro, 2018.

RODRIGUES, R.; DE BRITO, J.; SARDINHA, M. Mechanical properties of structural concrete containing very fine aggregates from marble cutting sludge. Construction and Building Materials, v. 77, p. 349-356, 2015.

SOGANCIOGLU, M., YEL, E., AKSOY, S., UNAL, V. E. Enhancement of concrete properties by waste physicochemical treatment sludge of travertine processing wastewater. Journal of Cleaner Production, 112, 2016, 575-580. 